Pacific Journal of Mathematics

A GENERALIZED FATOU THEOREM FOR BANACH 


\title{
A GENERALIZED FATOU THEOREM FOR BANACH ALGEBRAS
}

\author{
Donald Curtis TaYlor
}

Let $B$ denote a commutative, semisimple Banach algebra with unit and let $I$ be a fixed closed ideal in $B$. In the maximal ideal space $M_{B}$ of $B$, fix a compact set $X$ and put $E=X \cap h(I)$, where $h(I)$ is the hull of $I$. The main result of this note is the following

Theorem 1.1. Let $I$ have an approximate unit that is uniformly bounded by the constant $C$ and let $g$ be a nonnegative continuous function on $X$ of sup-norm $<1$ that vanishes on $E$. If $h$ is an element of $I$ and $\delta>0$, then there exists an element $f$ in $I$ such that

(1) $\|f\| \leqq C$

(2) $\operatorname{Re} \hat{f}(x) \geqq g(x)+|\operatorname{Im} \hat{f}(x)| \quad(x \in X)$

(3) $\|f h-h\|<\delta$.

Here $\hat{f}$ denotes the Gelfand transform of an element $f$ in $B$, \|\| denotes the norm in $B$, and \|\|$_{\infty}$ denotes the sup-norm in the space of complex, continuous functions on $X$.

1. A theorem of Fatou. Let $A$ denote the sup-norm algebra of continuous functions on the closed unit disc which are analytic on the open disc, and let $J=J(E)$ be the ideal of functions in $A$ which vanish on $E$, a closed set of Lebesgue measure 0 on the unit circle. In $J$ there exists a sequence of functions, each of sup-norm $\leqq 1$, which converges uniformly to the constant function 1 on compact subsets of the complement of $E$; that is, $J$ has an approximate unit. This fact may be deduced from a classical theorem of Fatou which guarantees the existence of a function in $A$ which vanishes precisely on $E$ and has positive real part elsewhere. The results in this paper stem from the observation that a reverse implication holds. By using only the existence of an approximate unit in $J$ and the fact that $E$ is a hull (This latter fact follows from the F. and M. Riesz theorem, for example.), we obtain the following generalized Fatou theorem for $A$ : if $g$ is a nonnegative continuous function on the closed unit disc of supnorm $<1$ that vanishes on $E$, then there exists an $f$ in $J$ such that $\|f\|_{\infty} \leqq 1$ and $\operatorname{Re} f \geqq g+|\operatorname{Im} f|$.

Because of the central role played by approximate units, an analogous result can be established with surprising ease in the setting of a general Banach algebra. Specifically, let $B$ denote a commutative, semisimple Banach algebra with unit and let $I$ be a fixed closed ideal in $B$. In the maximal ideal space $M_{B}$ of $B$, fix a compact set $X$ and 
put $E=X \cap h(I)$, where $h(I)$ is the hull of $I$. Our main result is

THEOREM 1.1. Let I have an approximate unit that is uniformly bounded by the constant $C$ and let $g$ be a nonnegative continuous function on $X$ of sup-norm $<1$ that vanishes on $E$. If $h$ is an element of $I$ and $\delta>0$, then there exists an element $f$ in I such that

(1) $\|f\| \leqq C$

(2) $\operatorname{Re} \hat{f}(x) \geqq g(x)+|\operatorname{Im} \hat{f}(x)| \quad(x \in X)$

(3) $\|f h-h\|<\delta$.

Here $\hat{f}$ denotes the Gelfand transform of an element $f$ in $B,\|\|$ denotes the norm in $B$, and \|\|$_{\infty}$ denotes the sup-norm in the space of complex, continuous functions on $X$. (For definitions and concepts we refer the reader to $[2$, p. 80] and [3].)

P. C. Curtis and A. Figá-Talamanca have already proved, by an application of their factorization theorem (see [1, p. 171]), a version of Theorem 1.1. They proved that if $A$ is a commutative semisimple Banach algebra with approximate unit, then the Gelfand transforms of elements of $A$ vanish arbitrarily slowly at infinity [1, Th. 4.1 and Th. 4.3, p. 180]. But their argument apparently does not give information about conditions (1), (2), and (3) of Theorem 1.1. For our applications this is crucial because conditions (1), (2), and (3) enable us to give a useful characterization of an approximate unit in $I$ (see Corollary 2.4). Furthermore, condition (2) gives us information about $\operatorname{Re} \hat{f}$. This is important because we need estimates on the supremum norm of $\exp (\hat{f})$. These estimates and condition (1) provide the information necessary to prove the interpolation Theorem 2.5.

2. Proof of Theorem 1.1. We will first give a precise definition of an approximate unit in $I$ and then we will state and prove two preliminary results.

Definition 2.1. The closed ideal $I$ is said to have an approximate unit, if there exists a real number $C \geqq 1$ and a collection $\left\{e_{\lambda}: \lambda \in \Lambda\right\}$ of elements of $I$, where the index set $\Lambda$ is a directed set, such that the following two conditions are satisfied: $\left\|e_{\lambda}\right\| \leqq C$, for each $\lambda$, and $\lim e_{\lambda} f=f$, for $f \in I$.

Lemma 2.2. If $S$ is a compact subset of $M_{B} \backslash h(I)$ and $\left\{e_{\lambda}\right\}$ is an approximate unit in $I$, then $\left\{\hat{e}_{\lambda}\right\}$ converges uniformly to 1 on $S$.

Proof. For each $x$ in $S$ choose an $f_{x}$ belonging to $I$ such that $\hat{f}_{x}(x)=1$ and then define

$$
V_{x}=\left\{y \in M_{B}:\left|\hat{f}_{x}(y)\right|>1 / 2\right\} .
$$


The family of sets $\left\{V_{x}: x \in S\right\}$ is an open cover of $S$ and therefore, by the compactness of $S$, there exists a finite subcover

$$
\left\{V_{x_{1}}, V_{x_{2}}, \cdots, V_{x_{n}}\right\}
$$

of $S$. Let $\left\{f_{x_{1}}, f_{x_{2}}, \cdots, f_{x_{n}}\right\}$ denote those elements in $I$ from which (2.2) is defined. It then follows that the inequality

$$
\left|1-\hat{e}_{\lambda}(y)\right|<2 \max \left\{\left\|f_{x_{j}}-f_{x_{j}} e_{\lambda}\right\|\right\} \quad(j=1,2,3, \cdots, n)
$$

holds for each $y$ in $S$. Since $\lim e_{\lambda} f_{x_{j}}=f_{x_{j}}$, for $j=1,2, \cdots, n$, we conclude that $\left\{\hat{e}_{\lambda}\right\}$ converges uniformly to 1 on $S$. Hence our proof is complete.

LEMMA 2.3. Let I have an approximate unit that is uniformly bounded by the constant $C$. If $K$ is a compact $G_{\hat{o}}$ subset of $M_{B}$ that contains $h(I)$, then there is a closed ideal $I_{0}$ in $B$ such that

(1) $I_{0} \subset I$,

(2) $h\left(I_{0}\right)$ is a compact $G_{j}$ subset of $M_{B}$,

(3) $h\left(I_{0}\right) \subset K$, and

(4) $I_{0}$ has a countable approximate unit that is uniformly bounded by $C$.

Proof. Since $K$ is a compact $G_{\delta}$ subset of $M_{B}$, there exists a descending sequence $\left\{V_{n}\right\}$ of open subsets of $M_{B}$ such that $K=\bigcap V_{n}$. Let $\left\{e_{\lambda}\right\}$ be an approximate unit of $I$ that is uniformly bounded by $C$. Then, by virtue of Lemma 2.2 , there exists an $e_{\lambda_{1}}$ in $I,\left\|e_{\lambda_{1}}\right\| \leqq C$, such that $\left|1-\hat{e}_{\lambda_{1}}\right|<1 / 2$ on $M_{B} \mid V_{1}$. Suppose that $e_{\lambda_{1}}, e_{\lambda_{2}}, \cdots, e_{\lambda_{n}}$ have been defined in $I$. Since $\lim e_{\lambda} e_{\lambda_{j}}=e_{\lambda_{j}}$ for $j=1,2, \cdots, n$, it follows that there exists (by Lemma 2.2) an $e_{\lambda_{n+1}}$ in $I$, $\left\|e_{\lambda_{n+1}}\right\| \leqq C$, such that $\left|1-\hat{e}_{\lambda_{n+1}}\right|<1 / 2$ on $M_{B} \backslash V_{n+1}$ and such that the inequality

$$
\left\|e_{\lambda_{j}} e_{\lambda_{n+1}}-e_{\lambda_{j}}\right\|<1 / 2^{n+1}
$$

holds for $j=1,2, \cdots, n$. Thus, by induction, we have defined a sequence of elements $\left\{e_{\lambda_{n}}\right\}$ in $I,\left\|e_{\lambda_{n}}\right\| \leqq C$, such that $e_{\lambda_{n}} e_{\lambda_{j}} \rightarrow e_{\lambda_{j}}$ as $n \rightarrow \infty(j=1,2,3, \cdots)$ and such that $\left\{\hat{e}_{\lambda_{n}}\right\}$ converges pointwise to 1 on $M_{B} \backslash K$. It is easy to show that the subset $I_{0}$ of $I$ defined by

$$
I_{0}=\left\{f \in I: \lim e_{\lambda_{n}} f=f\right\}
$$

is a closed ideal in $B$ that satisfies (1), (3), and (4). To see that $I_{0}$ satisfies (2), we observe that $h\left(I_{0}\right)=\bigcap_{n=1}^{\infty}\left\{x \in M_{B}:\left|\hat{e}_{\lambda_{n}}(x)\right|<1 / n\right\}$. Hence our proof is complete.

Proof of Theorem 1.1. By virtue of Lemma 2.3 we may clearly assume that $E$ is a compact $G_{\dot{o}}$ subset of $M_{B}$ and $g$ vanishes precisely 
on $E$.

Let $0<\lambda<1 / 4 C$ and $\varepsilon=\min \left\{1 / 32,\left(1-\|g\|_{\infty}\right) / 2\right\}$. Let $K_{p}$ denote the compact subset of $X$ defined by

$$
K_{p}=\left\{x \in X: g(x) \geqq(1-\lambda)^{p-1} / 8\right\} \quad(p=1,2,3, \cdots) .
$$

We shall by induction construct a sequence of elements $e_{1}, e_{2}, e_{3}, \cdots$ in $I$ and a sequence of compact subsets $D_{1}, D_{2}, D_{3}, \cdots$ of $X \backslash E$ such that for each positive integer $p$ the following hold:

(a) $\left\|e_{p}\right\| \leqq C$ and $\left\|e_{p} h-h\right\|<\delta$.

(b) $K_{p+1} \cup D_{p} \subset D_{p+1}$.

(c) $\operatorname{Re} \hat{e}_{p}>1-\varepsilon^{p}$ and $\left|\operatorname{Im} \hat{e}_{p}\right|<\varepsilon^{p}$ on $D_{p}$.

(d) $\sum_{k=1}^{p} \lambda(1-\lambda)^{k-1}\left|\hat{e}_{k}\right| \leqq(1 / 32) \cdot(1-\lambda)^{p}$ on $X \backslash D_{p+1}$.

Let $D_{1}=K_{1}$. Then there exists, by virtue of Lemma 2.2, an element $e_{1}$ in $I$ that satisfies conditions (a) and (c). Suppose that $e_{1}, e_{2}, e_{3}, \cdots, e_{n}$ have been defined in $I$ and that $D_{1}, D_{2}, \cdots, D_{p}$ have been defined in $X \backslash E$. Since $\sum_{k=1}^{p} \lambda(1-\lambda)^{k-1} \hat{e}_{k}$ is a continuous function on $X$ that vanishes on $E$, there exists a compact subset $D_{p+1}$ of $X \backslash E$ that satisfies conditions (b) and (d). Thus, as before, we have by virture of Lemma 2.2 an element $e_{p+1}$ in $I$ that satisfies conditions (a) and (c). Hence our construction is complete.

Let $f$ denote the element in $I$ defined by

$$
f=\sum_{k=1}^{\infty} \lambda(1-\lambda)^{k-1} e_{k} .
$$

It is clear that $\|f\| \leqq C$ and that $\|f h-h\|<\delta$. Therefore, we complete our proof by showing that

$$
\operatorname{Re} \hat{f}(x) \geqq g(x)+|\operatorname{Im} \hat{f}(x)| \quad(x \in X) .
$$

Let $x$ belong to $X$. If $x \in E$, then it is clear that (2.3) holds. If $x$ is an element of $D_{1}$, then (2.3) follows directly from (b) and (c). Otherwise, since $g$ vanishes precisely on $E$, there exists a positive integer $p$ such that $x$ belongs to $D_{p+1} \backslash D_{p}$. Consequently, by conditions (a), (c), and (d), we have

$$
\begin{aligned}
\operatorname{Re} \hat{f}(x) \geqq & \sum_{k=p+1}^{\infty} \lambda(1-\lambda)^{k-1} \operatorname{Re} \widehat{e}_{k}(x)-\lambda(1-\lambda)^{p-1}\left\|e_{p}\right\| \\
& \quad-\sum_{k=1}^{p-1} \lambda(1-\lambda)^{k-1}\left|\widehat{e}_{k}(x)\right| \\
& \geqq \sum_{k=p+1}^{\infty} \lambda(1-\lambda)^{k-1}\left(1-\varepsilon^{k}\right)-(1-\lambda)^{p-1} / 4-(1-\lambda)^{p-1} / 32 \\
& \geqq \sum_{k=p+1}^{\infty} \lambda(1-\lambda)^{k-1}-\sum_{k=p+1}^{\infty} \varepsilon \lambda(1-\lambda)^{k-1} \varepsilon^{k-1}-(9 / 32) \cdot(1-\lambda)^{p-1} \\
& \geqq(1-\lambda)^{p}-\varepsilon(1-\lambda)^{p-1}-(9 / 32) \cdot(1-\lambda)^{p-1} \\
& \geqq(14 / 32) \cdot(1-\lambda)^{p-1}
\end{aligned}
$$


and

$$
\begin{aligned}
|\operatorname{Im} \hat{f}(x)| & \leqq \sum_{k=p+1}^{\infty} \lambda(1-\lambda)^{k-1} \varepsilon^{k}+(1-\lambda)^{p-1} / 4+(1-\lambda)^{p-1} / 32 \\
& \leqq(5 / 16) \cdot(1-\lambda)^{p-1} .
\end{aligned}
$$

Since $x$ does not belong to $K_{p}$, we see by combining (2.4) and (2.5) that (2.3) holds.

CoROLlaRY 2.4. If I has an approximate unit that is uniformly bounded by the constant $C$, then $I$ has an approximate unit $\left\{e_{\lambda}: \lambda \in \Lambda\right\}$, $\left\|e_{\lambda}\right\| \leqq C$, such that

$$
\operatorname{Re} \hat{e}_{\lambda} \geqq\left|\operatorname{Im} \hat{e}_{\lambda}\right|
$$

on $M_{B}$ for each $\lambda$.

Proof. Let $\left\{h_{\alpha}: \alpha \in A\right\}$ be an approximate unit in $I$ and let $\Lambda$ be the directed set defined by

$$
\Lambda=\{(\alpha, n): \alpha \in A, n \text { a positive integer }\}
$$

under the usual partial ordering; that is, $\left(\alpha_{1}, n_{1}\right) \leqq\left(\alpha_{2}, n_{2}\right)$, if and only if, $\alpha_{1} \leqq \alpha_{2}$ and $n_{1} \leqq n_{2}$. For each $\lambda=(\alpha, n) \in \Lambda$ we may choose, by virtue of Theorem 1.1, an element $e_{\lambda}$ in $I,\left\|e_{\lambda}\right\| \leqq C$, such that

(a) $\left\|e_{\lambda} h_{\alpha}-h_{\alpha}\right\|<1 / n$

(b) $\operatorname{Re} \hat{e}_{\lambda}(x) \geqq\left|\operatorname{Im} \hat{e}_{\lambda}(x)\right| \quad\left(x \in M_{B}\right)$.

Now for arbitrary $f \in I$ and $\varepsilon>0$, there is an $\alpha_{0} \in A$ such that

$$
\left\|h_{\alpha} f-f\right\|<\varepsilon / 4 C \quad \text { for } \alpha \geqq \alpha_{0} \text {. }
$$

Choose $\lambda_{0}=\left(\alpha_{0}, n\right)$, where $\|f\| / n<\varepsilon / 2$. Then for $\lambda=(\alpha, n) \geqq \lambda_{0}$ we have

$$
\begin{aligned}
\left\|e_{\lambda} f-f\right\| & =\left\|e_{\lambda} f-e_{\lambda} h_{\alpha} f+e_{\lambda} h_{\alpha} f-h_{\alpha} f+h_{\alpha} f-f\right\| . \\
& \leqq 2 C\left\|h_{\alpha} f-f\right\|+\|f\| \cdot\left\|e_{\lambda} h_{\alpha}-h_{\alpha}\right\|<\varepsilon .
\end{aligned}
$$

In other words, $\lim e_{\lambda} f=f$ for every $f \in I$. Hence our proof is complete.

THEOREM 2.5. Suppose I has an approximate unit that is uniformly bounded by the constant $C$ and suppose $g$ is an element in $B$. If $\Delta$ is a positive continuous function on $X$ such that $\Delta \geqq|\hat{g}|$ on $E$ and $\varepsilon>0$, then there exists an element $f$ in $B$ such that

(1) $\hat{f}=\hat{g}$ on $E,|\hat{f}| \leqq \Delta$ on $X$, and

(2) $\|f\| \leqq\|p\|_{\infty}^{C}\|g\|+\varepsilon$.

Here $p$ is the positive continuous function on $X$ defined by $p(x)=$ $\max \{1,|\hat{g}(x)| / \Delta(x)\}$. 
Proof. Since $\log (p)$ is a nonnegative continuous function on $X$ that vanishes on $E$, we have by virtue of Theorem 1.1 an element $h$ in $I$ such that $-\operatorname{Re} \hat{h} \leqq-\log (p)$ on $X$ and such that the norm $\|h\| \leqq C \cdot \log \|p\|_{\infty}+\eta$, where $\eta=\log \left(1+\varepsilon /\|p\|_{\infty}^{c}\|g\|\right)$. Set $f=$ $g \cdot \exp (-h)$. It is clear that $\hat{f}|E=\hat{g}| E$ and since $|\hat{g}(x)| / p(x) \leqq \Delta(x)$, $x \in X$, the inequalities

$$
|\hat{f}(x)|=|\hat{g}(x)| \exp (-\operatorname{Re} \hat{h}(x)) \leqq|\hat{g}(x)| / p(x) \leqq \Delta(x)
$$

hold, $x \in X$. We complete the proof by showing (2) holds. To see this, we observe that the norm

$$
\|f\| \leqq\|g\| \exp \|h\| \leqq\|g\| \exp \left(\log \|p\|_{\infty}^{C}+\eta\right) \leqq\|p\|_{\infty}^{C}\|g\|+\varepsilon .
$$

\section{REFERENCES}

1. P. Curtis and A. Figá-Talamanca, Factorization theorems for Banach algebras, Function Algebras, F. T. Birtel, Editor, Scott, Foresman and Co., Chicago, 1966, 169185.

2. K. Hoffman, Banach Spaces of Analytic Functions, Prentice-Hall, Englewood Cliffs, New Jersey, 1962.

3. C. Rickart, General Theory of Banach Algebras, Van Nostrand, Princeton, New Jersey, 1960.

Received November 27, 1967. This note is a result of the author's dissertation research under the direction of Professor J. H. Wells, to whom the author is especially grateful.

UNIVERSITY OF MISSOURI

Columbia Missouri 


\title{
PACIFIC JOURNAL OF MATHEMATICS
}

\author{
EDITORS
}

\author{
H. ROYDEN \\ Stanford University \\ Stanford, California
}

\author{
J. P. JANS \\ University of Washington \\ Seattle, Washington 98105
}

\section{J. DUGUNDJI}

Department of Mathematics University of Southern California Los Angeles, California 90007

\section{RICHARD ARENS}

University of California Los Angeles, California 90024

\section{ASSOCIATE EDITORS}

\author{
E. F. BECKENBACH
}

B. H. NEUMANN

F. WoLF

K. YosidA

\section{SUPPORTING INSTITUTIONS}

\author{
UNIVERSITY OF BRITISH COLUMBIA \\ CALIFORNIA INSTITUTE OF TECHNOLOGY \\ UNIVERSITY OF CALIFORNIA \\ MONTANA STATE UNIVERSITY \\ UNIVERSITY OF NEVADA \\ NEW MEXICO STATE UNIVERSITY \\ OREGON STATE UNIVERSITY \\ UNIVERSITY OF OREGON \\ OSAKA UNIVERSITY \\ UNIVERSITY OF SOUTHERN CALIFORNIA
}

\author{
STANFORD UNIVERSITY \\ UNIVERSITY OF TOKYO \\ UNIVERSITY OF UTAH \\ WASHINGTON STATE UNIVERSITY \\ UNIVERSITY OF WASHINGTON \\ AMERICAN MATHEMATICAL SOCIETY \\ CHEVRON RESEARCH CORPORATION \\ TRW SYSTEMS \\ NAVAL WEAPONS CENTER
}

Mathematical papers intended for publication in the Pacific Journal of Mathematics should be in typed form or offset-reproduced, double spaced with large margins. Underline Greek letters in red, German in green, and script in blue. The first paragraph or two must be capable of being used separately as a synopsis of the entire paper. It should not contain references to the bibliography. Manuscripts, in duplicate if possible, may be sent to any one of the four editors. All other communications to the editors should be addressed to the managing editor, Richard Arens, University of California, Los Angeles, California 90024.

Each author of each article receives 50 reprints free of charge; additional copies may be obtained at cost in multiples of 50 .

The Pacific Journal of Mathematics is published monthly. Effective with Volume 16 the price per volume (3 numbers) is $\$ 8.00$; single issues, $\$ 3.00$. Special price for current issues to individual faculty members of supporting institutions and to individual members of the American Mathematical Society: $\$ 4.00$ per volume; single issues $\$ 1.50$. Back numbers are available.

Subscriptions, orders for back numbers, and changes of address should be sent to Pacific Journal of Mathematics, 103 Highland Boulevard, Berkeley 8, California.

Printed at Kokusai Bunken Insatsusha (International Academic Printing Co., Ltd.), 7-17, Fujimi 2-chome, Chiyoda-ku, Tokyo, Japan.

PUBLISHED BY PACIFIC JOURNAL OF MATHEMATICS, A NON-PROFIT CORPORATION

The Supporting Institutions listed above contribute to the cost of publication of this Journal, but they are not owners of publishers and have no responsibility for its content or policies. 


\section{Pacific Journal of Mathematics}

Vol. 26, No. 2 December, 1968

Seymour Bachmuth and Horace Yomishi Mochizuki, Kostrikin's theorem on

Engel groups of prime power exponent ....................

Paul Richard Beesack and Krishna M. Das, Extensions of Opial's inequality ...................................... 215

John H. E. Cohn, Some quartic Diophantine equations .............. 233

H. P. Dikshit, Absolute $(C, 1) \cdot\left(N, p_{n}\right)$ summability of a Fourier series and its conjugate series ............................... 245

Raouf Doss, On measures with small transforms ................. 257

Charles L. Fefferman, $L_{p}$ spaces over finitely additive measures........ 265

Le Baron O. Ferguson, Uniform approximation by polynomials with integral coefficients. II...................................

Takashi Ito and Thomas I. Seidman, Bounded generators of linear

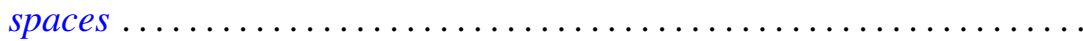

Masako Izumi and Shin-ichi Izumi, Nörlund summability of Fourier series ..........................................

Donald Gordon James, On Witt's theorem for unimodular quadratic

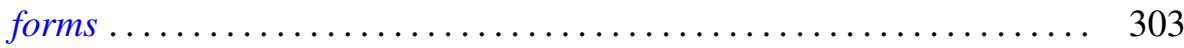

J. L. Kelley and Edwin Spanier, Euler characteristics .............. 317

Carl W. Kohls and Lawrence James Lardy, Some ring extensions with matrix

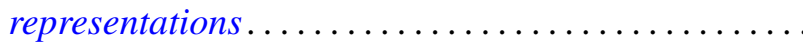

Ray Mines, III, A family of functors defined on generalized primary groups ....

Louise Arakelian Raphael, A characterization of integral operators on the space of Borel measurable functions bounded with respect to a weight function....

Charles Albert Ryavec, The addition of residue classes modulo $n .$.

H. M. (Hari Mohan) Srivastava, Fractional integration and inversion formulae associated with the generalized Whittaker transform ...

Edgar Lee Stout, The second Cousin problem with bounded data ...

Donald Curtis Taylor, A generalized Fatou theorem for Banach

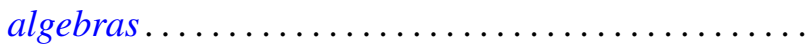

Bui An Ton, Boundary value problems for elliptic convolution equations of Wiener-Hopf type in a bounded region...

Philip C. Tonne, Bounded series and Hausdorff matrices for absolutely convergent sequences... 